\title{
Nursing Intervention for Caregivers of Post Autologous Bone Marrow Transplantation Patients at Home
}

\author{
Asmaa Farouk Mohamed ${ }^{1}$, Nawal Soliman², Hemat Abd-El-Moneem El-Sayied ${ }^{2}$, Asmaa Talaat ${ }^{3}$ \\ ${ }^{1}$ M.Sc.N., Community Health Nursing, ${ }^{2}$ Professors of Community Health Nursing, ${ }^{3}$ Lecturer of Community Health \\ Nursing, Faculty of Nursing-Ain Shams University, Cairo, Egypt
}

\begin{abstract}
Background: Autologous bone marrow transplantation is a curative procedure forhematological diseases and immune deficiencies. The unique and intensive nature of this treatment requires distinctive care during and post the entire transplant course. Nursing intervention for caregivers post autologous bone marrow transplantation patients at home is an important component of the care that improves and develops knowledge and practice of the caregivers, to take care of the patients in order to help them followthe demanding treatment plan to reach recovery.
\end{abstract}

Aim to evaluate the effect of nursing intervention for caregivers of post-autologous bone marrow transplantation patients at home.

Material and Method: A Quasi-experimental study was carried out among convenient sample of 143 patients and their caregivers who attended the follow up clinic during the first six months post autologous bone marrow transplantation. The study was conducted among patients and their caregivers in three different hospitals Sheikh Zayed Specialized Hospital, National oncology institute, and Nasser institute at outpatient's follow-up clinics.A self-administered questionnaire of patients and their caregivers' demographic data, and reported checklist of caregivers' knowledge and practices toward post-autologous bone marrow transplantation patients at home.

Results: There was astatistically significant difference between pre and post nursing intervention, which indicate improvement in caregivers' knowledge and practice post implementation of the nursing intervention program, and positive correlation between their knowledge and practice.

Conclusion and Recommendations: Although caregivers had adequate knowledge, practice on some aspects, gaps were identified. There is a need for educational interventions and discharge plan to upgrade knowledge and practices of the caregivers of post autologous bone marrow transplantation patient at home.

Keywords: Autologous bone marrow transplantation, caregivers, nursing intervention, home.

\section{Introduction}

Since the onset and progression of bone marrow transplantation it was evident from the 1950s to early 1960 s that nurses play an important role within the multi professional team caring for patients and their families go through this treatment. ${ }^{1}$ Bone marrow transplant is an umbrella term for the grouping of a variety of procedures. These transplants use stem cells from bone marrow, peripheral blood or cord blood and more recently the procedure has been called haemopoietic stem cell transplantation (HSCT) The type of treatment is then classified based on the origin of the stem cells, autologous being derived from the recipient himself. ${ }^{2}$

The family does need support, and need pre- and post-HSCT education and psychosocial intervention, All stages of the transplant process will affect family members. The effect of this severe medical procedure will clearly extend beyond the person concerned to the entire family network. ${ }^{3}$ In the post-transplant duration, it is important to have a distinct pattern of evaluation 
to assess disease condition and for any post-transplant complications. ${ }^{4}$ Increasing caregivers' confidence and competence require training in the skills they need to provide care to the patient. Past studies have repetitively shown that caregivers often express attentiveness in, and have a need for education and support programs. ${ }^{5}$

The population of Egypt exceeded 100 million in 2020. There are fifteen transplant centers and the transplant rate is 8.4 million. Bone marrow transplantation in Egypt began on a restricted scale in 1989. In 1997, the rate of transplantation increased significantly. ${ }^{6}$ Specific attention has developed towards educating the longterm survivors and their caregivers in which nursing intervention plays a significant role because medical treatment activities are more in the background and dayto-day questions have to be dealt with. ${ }^{1}$

Research Hypothesis: The nursing intervention program will improve the caregivers' level of knowledge and practices in caring of post Autologous Bone Marrow Transplantation Patients at Home.

\section{Materials and Method}

A quasi-experimental study was carried out among 143 patients and their caregivers at outpatient followup clinics in three biggest hospitals in Cairo, Egypt for autologous bone marrow transplantation patients, Sheikh Zayed Specialized Hospital, National Oncology Institute, and Nasser Institute. An official written letter including the title and purpose of the study obtained from the dean of Faculty of Nursing, Ain Shams University to the get the approval form directors of the mention hospitals to conduct the study. A consent was obtained from each participant (patient and caregiver).

The 143 (patients and caregivers)were divided into 6 groups The actual process of data collection was carried out in the period from February 2019 to July 2019 The intervention program consisted of 17 hours (5 hours theoretical, 12 hours practical). Educational media were used such as poster, PowerPoint, laptop, handout Arabic booklet, videos.

The tool was developed by the researcher, based on reviewing related literatures and experts' opinions, written in Arabic language, and Completed under supervision of the researcher through group interview. A self-administered questionnaire of patients and their caregivers' demographic data includes 10 questions. Self-Reported checklist of caregivers' practices and knowledge toward post autologous bone marrow transplantation patients at home. Caregivers' Knowledge consisted of 15 questions with Cronbach's value 0.78 .

Answers was coded as follow: poor $=1$, good $=2$. Caregivers' practices consisted of 90 questions including:- patient transfer, Central venous catheter care, Meals preparation and diet restrictions, Personal hygiene, Medication administration, and Following Infection control. With Cronbach's value 0.76.

The total score was divided into two scale: Poor $>$ $60 \%$ Good $\geq 60 \%$.

The collected data were organized; tabulated and analyzed using software, the appropriate statistical tests was the Statistical Package for Social Science SPSS (version 25). The statistical analysis includes; percentage (\%), Chi-Square test $\left(\mathrm{X}^{2}\right)$, Proportion probability $\mathrm{P}$ value.

\section{Significance of results was described as follows:}

- Not-significant difference obtained at $\mathrm{p}>0.05$.

- $\quad$ Significant difference obtained at $\mathrm{p}<0.05$.

Evaluation the level of improvement in caregivers' knowledge, practice, was done by giving post-test similar to pre-test. Evaluation was administered to the caregivers after completion of the program in order to estimate the effect of the program on the caregivers, and recognize the benefit of the program and what are the ways of obstacles to lack of implementation.

\section{Results}

Table (1) shows that, the median and range of age of the studied patients was 48 (21-50) years, in relation to gender, $53.1 \%$ were males, and $67.1 \%$ were married, while $58 \%$ had 3-4 children, as regards educational level $42 \%$ of them had university education. Concerning occupation, $37.8 \%$ were employees, with $70.6 \%$ had sufficient monthly income.

Regarding the caregivers: Illustrates that, the median and rang of age of the studied caregivers was 47 (18-60)years. $68.5 \%$ of the caregivers were females. Regarding Kin-relation with the patient $30.8 \%$ were spouse. Related to educational level $41.9 \%$ of the studied sample were secondary education. In relation to the marital status, $41.9 \%$ were married, Concerning of job $34.3 \%$ were employees, and $76.9 \%$ of time of care were full time. 
Figure (1) displays that, pre interventional program good knowledge and practice was $27.2 \%$, $36.4 \%$, respectively, while post implementation of an interventional program good knowledge and practice was $87.5 \%, 89.3 \%$ respectively.

Table (2) Clarifies there was statistical significant relation between pre and post of total caregivers' demographic characteristics (age, gender,educational level, occupation, time of care) and total caregivers' knowledge and practice score. However marital status, kin-relation, shows no significant effects on caregivers' knowledge and practice.

Table (3) Illustrates that there was statistical significant positive correlation between pre \& post-test of total caregivers' knowledge and practices at $\mathrm{P}<0.001$.

Table (1): Distribution of the patients and their caregivers according to their demographic characteristics $(n=143)$.

\begin{tabular}{|l|c|c|}
\hline \multirow{2}{*}{ Demographic characteristics } & Patients & Caregivers \\
\cline { 2 - 3 } & N (\%) & N (\%) \\
\hline Median age, yrs. (range) & $48(21-50)$ & $47(18-60)$ \\
\hline Gender: & & \\
Male & $76(53.1)$ & $45(31.5)$ \\
Female & $67(46.9)$ & $98(68.5)$ \\
\hline Marital status & & \\
Single & $19(13.3)$ & $28(19.6)$ \\
Married & $96(67.1)$ & $60(41.9)$ \\
Divorced & $12(8.4)$ & $29(20.3)$ \\
Widow & $16(11.2)$ & $26(18.2)$ \\
\hline
\end{tabular}

\begin{tabular}{|c|c|c|}
\hline \multirow{2}{*}{ Demographic characteristics } & Patients & Caregivers \\
\hline & $\mathbf{N}(\%)$ & $\mathbf{N}(\%)$ \\
\hline \multicolumn{3}{|l|}{ Number of children } \\
\hline Non & $21(14.7)$ & \\
\hline $1-2$ & $34(23.8)$ & \\
\hline $3-4$ & $83(58.0)$ & \\
\hline$\leq 5$ & $5(3.5)$ & \\
\hline \multicolumn{3}{|l|}{ Educational level: } \\
\hline Does not Read or write & $7(4.9)$ & $7(4.9)$ \\
\hline Read \& write & $3(2.1)$ & $6(4.2)$ \\
\hline Primary & $19(13.3)$ & $42(29.4) 60$ \\
\hline Secondary & $54(37.7)$ & (41.9) \\
\hline University & $60(42.0)$ & $28(19.6)$ \\
\hline \multicolumn{3}{|l|}{ Occupation } \\
\hline Jobless & $14(9.8)$ & $21(14.7)$ \\
\hline Employee & $87(60.8)$ & $88(61.5)$ \\
\hline Housewife & $42(29.4)$ & $34(23.8)$ \\
\hline \multicolumn{3}{|l|}{ Monthly income } \\
\hline Sufficient & $101(70 . .6)$ & \\
\hline Not sufficient & $42(29.4)$ & \\
\hline \multicolumn{3}{|l|}{ Kin-relation } \\
\hline Parent & & $22(15.4)$ \\
\hline Spouse & & $44(30.8)$ \\
\hline Children & & $33(23.0)$ \\
\hline Brother & & $2(1.4)$ \\
\hline Sister & & $19(13.3)$ \\
\hline Relatives & & $9(6.3)$ \\
\hline Friend & & $8(5.6)$ \\
\hline Paid- caregiver & & $6(4.2)$ \\
\hline \multicolumn{3}{|l|}{ Time of care } \\
\hline Full time & & $110(76.9)$ \\
\hline Part time & & $33(23.1)$ \\
\hline
\end{tabular}

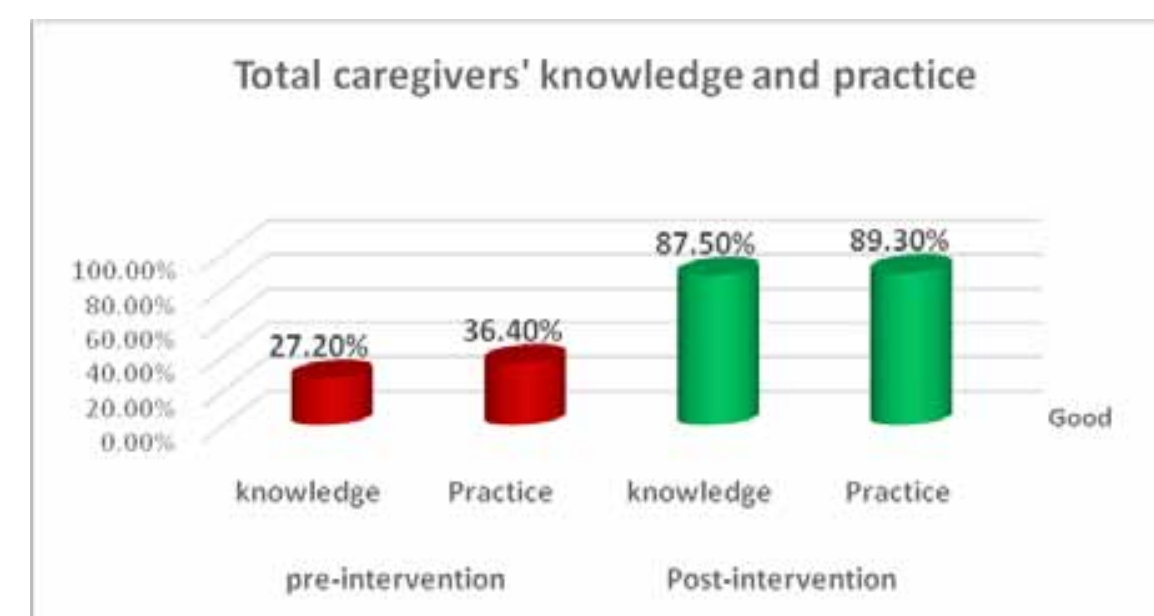

Figure (1): Distribution of total caregivers' knowledge and practice total score level regarding pre and post nursing intervention $(n=143)$. 
Table (2): Relation between caregivers' demographic characteristics and total caregivers' knowledge and practice score level pre $\&$ post interventional program $(n=143)$.

\begin{tabular}{|l|c|c|c|c|c|c|c|c|}
\hline \multirow{2}{*}{$\begin{array}{l}\text { Caregivers' demographic } \\
\text { characteristics }\end{array}$} & \multicolumn{3}{|c|}{ Total caregivers' knowledge } & \multicolumn{3}{c|}{ Total caregivers' practices } \\
\cline { 2 - 10 } & \multicolumn{2}{|c|}{ Pre-test } & \multicolumn{2}{|c|}{ Post-test } & \multicolumn{2}{|c|}{ Pre-test } & \multicolumn{2}{c|}{ Post-test } \\
\cline { 2 - 10 } & $\mathbf{X 2}$ & $\mathbf{P}$ & $\mathbf{X 2}$ & $\mathbf{P}$ & $\mathbf{X 2}$ & $\mathbf{P}$ & X2 & P \\
\hline Age & 82.500 & 0.000 & 89.277 & 0.000 & 123.779 & 0.001 & 80.920 & 0.001 \\
\hline Gender & 116.783 & 0.000 & 9.456 & 0.001 & 69.205 & 0.000 & 11.303 & 0.001 \\
\hline Marital status & 2.228 & 0.136 & 2.145 & 0.143 & 2.168 & 0.141 & 1.597 & 0.206 \\
\hline Educational level & 124.415 & 0.000 & 31.069 & 0.000 & 105.187 & 0.000 & 94.024 & 0.000 \\
\hline Occupation & 123.779 & 0.001 & 80.920 & 0.001 & 74.465 & 0.001 & 104.485 & 0.001 \\
\hline Kin-relation & 0.509 & 0.476 & 0.901 & 0.088 & 0.653 & 0.419 & 1.293 & 0.255 \\
\hline Time of care & 105.187 & 0.000 & 94.024 & 0.000 & 33.784 & 0.001 & 65.534 & 0.001 \\
\hline
\end{tabular}

Not Significant $\mathrm{P}>0.05$ Significant $\mathrm{P}<0.05$

Table (3): Correlation between caregivers' knowledge and practices pre $\&$ post training program $(\mathrm{n}=143)$.

\begin{tabular}{|l|c|c|c|c|}
\hline \multirow{2}{*}{ Item } & \multicolumn{3}{|c|}{ Total caregivers' practice } \\
\cline { 2 - 5 } & \multicolumn{2}{|c|}{ Pre-test } & \multicolumn{2}{c|}{ Post-test } \\
\cline { 2 - 5 } & $\mathbf{R}$ & $\mathbf{P}$ & 0.915 & $\mathbf{P}$ \\
\hline Total caregivers' knowledge & 0.870 & 0.000 & 0.000 \\
\hline
\end{tabular}

\section{Discussion}

The current study illustrated that Table (1) the median and range of age of the studied patients was 48 (21-50) years, in relation to gender, around half of the patients were males, and about two third were married, while more than half had 3-4 children, as regards educational level less than half of them had university education. Concerning occupation, almost one third were employees, with more than two third had sufficient monthly income. This study was in agreement with previous studies. ${ }^{7,8}$

Regarding the caregivers Illustrates that, the median and rang of age of the studied caregivers was 47 (1860)years. More than two third of the caregivers were females. Regarding Kin-relation with the patient less than one third were spouse. Related to educational level below than half of the studied sample were secondary education. In relation to the marital status, less than half were married, Concerning of job almost one third were employees, and more than three quarter of time of care were full time. This study was in the consistent with previous studies. ${ }^{7,9,10}$ Similar findings also were reported in the studies conducted in USA. Becoming a caregiver was a second full-time occupation, as caregiving had become the priority in their lifetime. ${ }^{11}$

But another earlier study was in contrast to the current study, claiming that young caregivers typically have to juggle jobs, their own family commitments, middle-aged caregivers usually worry about missing workdays. Interruptions in work absence leave and reduced productivity. In addition to, limited income can place families at risk of care for non-compliance or of treatment related decision on the basis of income. ${ }^{12}$

Regarding caregivers' knowledge and practice Figure (1) displays that, most of the caregivers had good knowledge, and majority of them had good practice post-interventional program, indicating that the caregivers improved in their knowledge and practice after application of nursing interventional program. This could be because they got benefit of the program, and education outcomes. The level of good knowledge and practice were lower in pre-interventional program as mentioned in early study that Family caregivers often feel unprepared, have inadequate knowledge, and receive little guidance from the transplant team. Beside education should pass expertise, skills and 
details. Successful delivery of education is a dynamic process that depends on sufficient timing. The primary outcome identified in the majority of health education. Respondents show increased health awareness and make healthier decisions about their patients' health following intervention. So good education also increases patient/ caregiver self-efficacy, reduces anxiety by planning for transplantation, and increase the satisfaction of the patient. More long- term education results might include improvement in survival and transplantation morbidity, accessibility of health care, willingness of patients/ caregivers to return to work, and quality of life. ${ }^{12,13}$ other study revealed that the preparation of family caregivers for their position must include clear education, including skills training. Preparing caregivers should be an ongoing process such that benefits are maintained and education programmes develop as required. ${ }^{14}$

Concerning caregivers' demography Table (2) Clarifies there was statistical significant relation between pre and post of total caregivers' demographic characteristics (age, gender, educational level, occupation, time of care) and total caregivers' knowledge and practice score level. However marital status, kin-relation, shows no significant effects on caregivers' knowledge and practice. The finding was supported by other study conducted in USA Indicating that the caregiver does not necessarily discuss the gender position of the participants. This can be explained at least in part by the fact that the majority of caregivers are women, that caregivers themselves are viewed as a woman's position, and that male caregivers make less use of resources, including support groups, than women do. ${ }^{5}$

The same results were observed in early studies that educational and training needs would flow over time, driven by complex processes that characterize adult and family life trajectories. Only a few States provide financial aid to family members who perform the position of caregivers. Therefore, to give full-time care, caregiver has to leave the workforce to support the loved ones. Currently, the Health Care Management System offers some assistance to spouses who perform the function of caregivers. ${ }^{5,13}$ With regard to time of treatment. In addition, there were statistically significant differences between the pre-and post-intervention programme, the current research in the same line of the previous study showed that full-time caregivers offer more support and can apply the information acquired by the caregiver from the programme. ${ }^{14}$
There were no major variations in marital status, the relationship of caregivers and their expertise and experience in the current research. The findings show that, in accordance with the previous studies. It reported that there was no significant relation between marital status, and kin-relation of caregivers and their knowledge and practice. This may be due to the nature of the intimate relationship between the caregiver and the patient. It did not rely on the relationship. However, depending on the nature of the relationship between the patient and the caregiver, it could possibly lead to a complicated situation of caregiving that could affect the delivery of care, but did not influence awareness. ${ }^{5,9,13}$

Finally Table (3) Illustrates that there was strong positive correlation between pre \& post-test of total caregivers' knowledge and practices, the caregivers' total knowledge score was positively associated with the total practice score toward post autologous bone marrow transplantation patients at home. The higher the knowledge, the higher the practice, in which this shows that caregivers' practice is directly related to their knowledge as reported in the previous study ${ }^{12,13}$ In the most recent sense, a similar study was performed in the United States, which determined that there is a substantial association between the degree of education of caregivers and their practice in post-autologous bone marrow transplantation patients. Improved awareness and/or willingness to offer treatment to United States. ${ }^{12}$ In other previous study mentioned that Role preparedness has been studied in terms of how the development of knowledge and skills might protect the caregiver from role distress when the difficulty of care or the need for care is high. ${ }^{9}$

\section{Conclusion}

Based on the results of the current study and research hypothesis;implementation of nursing intervention program improved the knowledge and practices of the caregivers of postautologous bonemarrow transplantation patients at home,there was statistically significant differences between pre/post-nursing intervention post autologous bone marrow transplantation regarding caregivers' knowledge, practice. In addition, there was statistically significant relations between caregivers' demographic characteristics and total score level of caregivers' knowledge and practice in some parts, beside there was positive correlation between pre $\&$ post-test of total caregivers' knowledge and practices score level. Further research with a larger sample of caregivers 
from other governorates in Egypt are required in order to have a better understanding the needs of caregivers' knowledge and practices post autologous bone marrow transplantation patient at home.

\section{Conflict of Interest: Nil}

\section{Source of Funding: Nil}

Ethical Clearance: Obtained

\section{References}

1. Kenyon MI, Babic AL: Fliedner MC . The European Blood and Marrow Transplantation Textbook for Nursess. Under the Auspices of EBMT. Switzerland: Springer International Publishing; 2018. P XIII - XVI.https://doi.org/10.1007/978-3319-50026-3

2. Cutler TJ, Brown M. Haematology Nursing. UK: WILEY-BLACKWELL Publisher; 2012. P. 287.

3. Yong L. A Family Perspective on a Program for Bone Marrow Transplantation of Adults (Family Impact Analysis Series). Madison, WI: Policy Institute for Family Impact Seminars; 2003. P. 1.

4. Yarbro HC, Wujcik D, Gobel HB. Cancer Nursing, PRINCIPLES AND PRACTICE. Canada:Jones and Bartlett Publishers; 2011. P. 511.

5. Toseland WR, Haigler HD, Monahan JD. Education and Support Programs for Caregivers. Caregiving: Research, Practice, Policy. New York: Springer Publisher; 2011. P. 13-15.

6. Mahmoud HK, Fathy GM, Elhaddad A, Fahmy OA, Abdel-Mooti M, Abdelfattah $\mathrm{R}$ et al.: Hematopoietic Stem Cell Transplantation in Egypt: Challenges and Opportunities. Mediterranean Journal of Hematology and Infectious Diseases 2020, 12(1): e2020023:1-7 DOI: http://dx.doi. org/10.4084/MJHID.2020.023

7]J amani K, Onstad EL, Bar M, Carpenter AP, Krakow FE, Salit BR et al.: Quality of Life of Caregivers of Hematopoietic Cell Transplant Recipients. ELSEVIER. Biology Blood Marrow Transplant 24(2018)2271-2276.
8. Barban A, Coracin L, Musqueira P, Barban A, Ruiz L, Ruiz M. Analysis of the feasibility of early hospital discharge after autologous hematopoietic stem cell transplantation and the implications to nursing care. Revista Brasileira de Hematologia e Hemoterapia. Brazilian Journal of Hematology and Hemotherapy. ELSERVIER. Rev Bras Hematol Hemoter. 2014;36(4):264-268

9. Gemmill R, cooke L, William CA, Grant M: Informal Caregivers of Hematopoietic Cell Transplant Patients: A Review and Recommendations for Interventions and Research. Cancer Nurs. 2011 November; 34(6): E13-E21.1-15 doi:10.1097/ NCC.0b013e31820a592d.

10. Von D, Spath M, Nielsen, Fife B: The Caregiver's Role Across the Bone Marrow Transplantation Trajectory. Wolters Kluwer Health 2015; 1-9 DOI: 10.1097/NCC.0000000000000242.

11. LeSeure P, Chongkham-ang S: The Experience of Caregivers Living with Cancer Patients: A Systematic Review and Meta-Synthesis. J. Pers. Med. 2015, 5, 406-439; doi:10.3390/jpm5040406.

12. National Cancer Institute (NCI): Informal Caregivers in Cancer: Roles, Burden, and Support $\left(P D Q{ }^{\circledR}\right)$ : Supportive care - Health Professional Information [NCI]. https://www.uwhealth.org/ health/topic/nci/family-caregivers-in-cancerroles-and-challenges-pdq-supportive-care-healthprofessional-information-nci/ncicdr0000681705. html

13. Schoemans M, Finn L, Foster J, Roche-Green A, Bevans M, Kullberg Setal. AConceptualFramework and Key Research Questions in Educational Needs of Blood and Marrow Transplantation Patients, Caregivers, and Families. Biology Blood Marrow Transplant 2019;25: 1416_1423.

14. Berry L, Jacobson J. Supporting the Supporters: What Family Caregivers Need to Care for a Loved One With Cancer.Journal of Oncology Practice DOI: 10.1200/JOP.2016.017913; published online ahead of print at ascopubs.org/journal/jop on December 20, 2016; 35-41. 